\title{
Oridonin induces apoptosis and senescence in colorectal cancer cells by increasing histone hyperacetylation and regulation of p16, p21, p27 and c-myc
}

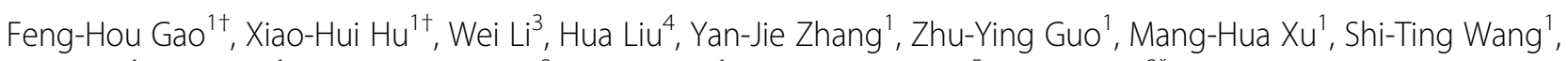
Bin Jiang ${ }^{1}$, Feng Liu' ${ }^{1}$, Ying-Zheng Zhao ${ }^{3}$, Yong Fang ${ }^{1}$, Fang-Yuan Chen ${ }^{5}$, Ying-Li Wu ${ }^{2 *}$

\begin{abstract}
Background: Oridonin, a tetracycline diterpenoid compound, has the potential antitumor activities. Here, we evaluate the antitumor activity and action mechanisms of oridonin in colorectal cancer.

Methods: Effects of oridonin on cell proliferation were determined by using a CCK-8 Kit. Cell cycle distribution was determined by flow cytometry. Apoptosis was examined by analyzing subdiploid population and terminal deoxynucleotidyl transferase-mediated dUTP nick end labeling assay. Senescent cells were determined by senescence-associated $\beta$-galactosidase activity analysis. Semi-quantitative RT-PCR was used to examine the changes of mRNA of p16, p21, p27 and c-myc. The concomitant changes of protein expression were analyzed with Western blot. Expression of $\mathrm{AcH} 3$ and $\mathrm{AcH} 4$ were examined by immunofluorescence staining and Western blots. Effects of oridonin on colony formation of SW1116 were examined by Soft Agar assay. The in vivo efficacy of oridonin was detected using a xenograft colorectal cancer model in nude mice.

Results: Oridonin induced potent growth inhibition, cell cycle arrest, apoptosis, senescence and colony-forming inhibition in three colorectal cancer cell lines in a dose-dependent manner in vitro. Daily i.p. injection of oridonin $(6.25,12.5$ or $25 \mathrm{mg} / \mathrm{kg})$ for 28 days significantly inhibited the growth of SW1116 s.c. xenografts in BABL/C nude mice. With western blot and reverse transcription-PCR, we further showed that the antitumor activities of oridonin correlated with induction of histone ( $\mathrm{H} 3$ and $\mathrm{H} 4$ ) hyperacetylation, activation of p21, p27 and p16, and suppression of c-myc expression.

Conclusion: Oridonin possesses potent in vitro and in vivo anti-colorectal cancer activities that correlated with induction of histone hyperacetylation and regulation of pathways critical for maintaining growth inhibition and cell cycle arrest. Therefore, oridonin may represent a novel therapeutic option in colorectal cancer treatment.
\end{abstract}

\section{Background}

Colorectal cancer (CRC) is one of the most frequently diagnosed malignancies in both men and women, with more than 1,000,000 new cases annually worldwide [1]. Advances in therapies over the past decade have led to improved outcomes for many patients. Although

\footnotetext{
* Correspondence: wuyingliwu@163.com

† Contributed equally

${ }^{2}$ Dept. of Pathophysiology, Key Laboratory of Cell Differentiation and Apoptosis of National Ministry of Education, Shanghai Jiao-Tong University School of Medicine (SJTU-SM), Shanghai 200025, PR China

Full list of author information is available at the end of the article
}

curative resection is the major treatment option, approximately half of all patients eventually develop distant metastases. Liver metastases (LM) occur in more than $50 \%$ of CRC patients, but curative liver resection is possible only in $15 \%$ of them, resulting in 5 -year survival rates of $30 \%$ on average [2-4]. Improving resectability rates and hopefully patient's prognosis by adding up front active chemotherapy and biological agents in metastatic CRC is a challenging opportunity for both medical and surgical oncologists [5]. Thus, effective new cytotoxic chemotherapy is needed for these diseases.

\section{C) Biomed Central}


The terpenoids constitute the largest family of natural products; over 22,000 individual compounds of this class have been described, and the number of defined structures has doubled every decade since the 1970s [6]. In plants, terpenoids represent a chemical defense against environmental stress and provide a repair mechanism for wounds and injuries. Interestingly, effective ingredients in several plant-derived medicinal extracts are also terpenoid compounds of monoterpenoid, sesquiterpenoid, diterpenoid, triterpenoid and carotenoid groups. Experimental study shows that many of them have strong anti-tumor activity [7]. For example, Tanshinone IIA, the major active diterpene quinine in the herbal product from the roots of Salvia miltiorrhiza, is a commonly used Chinese plant remedy which seems to have some activity against breast cancer $[8,9]$. Celastrol, a quinone methide triterpenoid, isolated from the Chinese Thunder of God Vine (Tripterygium wilfordii Hook F.), as well as triptolide, are currently being investigated in the search for prevention of tumor cell invasion [10]. Plant-derived terpenoids provide a challenging field to identify new potent natural anticancer compound for the therapy of colorectal cancer.

Oridonin, an ent-kaurane diterpenoid isolated from Rabdosia rubescens, is an important traditional Chinese herbal remedy. Studies showed that oridonin induced apoptosis in a variety of cancer cells including those from prostate, breast, non-small cell lung cancer, acute leukemia, glioblastoma multiforme and human melanoma cells. Cell culture experiments have indicated that oridonin inhibits cell cycle progression and induces apoptosis as well as enhance the phagocytosis of apoptotic cells by macrophages $[11,12]$. Oridonin has also immunosuppressive properties both in vitro and in vivo [13]. However, mechanisms underlying the antitumor activity of oridonin and whether oridonin has the anticolorectal cancer activity remain largely unknown.

In this report, we found that oridonin could induce potent growth inhibition, cell cycle arrest, apoptosis and senescence of colorectal cancer cells in vitro and in vivo. The antitumor activities of oridonin correlated with induction of histone ( $\mathrm{H} 3$ and $\mathrm{H} 4$ ) hyperacetylation, activation of p21, p27 and p16, and suppression of cmyc expression.

\section{Methods \\ Cell Culture and Reagents}

The colorectal cancer cell lines SW1116, HT29 and HCT116 from Shanghai Institutes for Biological Sciences were incubated in humidified room air containing $5 \% \mathrm{CO}_{2}$ at $37^{\circ} \mathrm{C}$ and cultured in McCOY'S 5A medium (Sigma, USA) supplemented with $10 \%$ fetal bovine serum (FBS) and $1 \%$ penicillin-streptomycin (GIBCO BRL, Grand Island,NY). Cells were routinely grown in
$100 \mathrm{~mm}$ plastic tissue culture dishes (Nunc, Roskilde, Denmark) and harvested with a solution of trypsinEDTA when they were in logarithmic phase of growth. Cells were maintained at these culture conditions for all experiments. Oridonin (purity $>98 \%$ ) was purchased from CHENGDU MUST BIO-TECHNOLOGY CO. LTD. It was dissolved in DMSO at a stock concentration of $100 \mathrm{mmol} / \mathrm{L}$ and store at $-20^{\circ} \mathrm{C}$. The stock solution was further diluted with cell culture medium to yield final oridonin concentrations.

\section{Cell Proliferation Assay}

Cells were seeded into 96 -well plates at 2,000 to 3,000 live cells per well and treated with Oridonin (6.25-100 $\mu \mathrm{M})$ for 3 days. The antiproliferative effect of Oridonin was assessed using Cell Count Kit-8 (Dojindo Molecular Technologies, Inc., Gaithersburg, MD).

\section{Cell Cycle Analysis with Flow Cytometry}

Cells treated with or without Oridonin (12.5 and 25 $\mu \mathrm{mol} / \mathrm{L}$ ) were harvested for flow cytometry analysis on day 1 . Cells were fixed and stained with $0.1 \mathrm{mg} / \mathrm{mL}$ propidium iodide for DNA analysis with Becton Dickinson FACScan (Franklin Lakes, NJ) as described previously [14].

\section{Detection of Apoptosis}

Apoptosis was evaluated with flow cytometry and on cell smears using the terminal deoxynucleotidyl transferase-mediated dUTP nick end labeling assay (In situ Cell Death Detection kit, AP; Boehringer Mannheim $\mathrm{GmbH}$, Mannheim, Germany). Samples were incubated with 50 $\mu \mathrm{L}$ of reaction mixture in a humidified chamber at $37^{\circ} \mathrm{C}$ for 90 minutes as described previously [15]. The percentage of apoptotic cells was determined by counting at least 1,000 cells from 10 to 20 high-power fields $(\times 200)$ under both phase-contrast and fluorescent microscopy.

\section{Cell Senescence Assay}

Senescence-associated expression of $\beta$-galactosidase activity [16] was done with a Senescence Detection kit (BioVision, Mountain View, CA) on fixed cells treated with or without Oridonin (12.5 and $25 \mu \mathrm{mol} / \mathrm{L})$. The development of cytoplasmic blue was detected and photographed using a Nikon (Nikon Instruments, Inc., Lewisville, TX) inverted microscope equipped with a color CCD camera.

\section{RNA Extraction and Semi-quantitative RT-PCR}

Total RNA was extracted from cell cultures using TRI REAGENT (Molecular Research Center, Inc., OH) according to the manufacturer's protocol. The mRNA levels of the genes analyzed were measured by RT-PCR amplification. Sequences for mRNAs from the 
nucleotide data bank (National Center for Biotechnology Information) were used to design primer pairs for RTPCR reactions (Primer Express, Applied Biosystems, CA). The following specific oligonucleotide primers were used respectively for p16 (p16-F: 5'-CAC GGC CGC GGC CCG GGG TC -3' and p16-R: 5'-GGC CCG GTG CAG CAC CAC CA -3'), p21(p21-F: 5'-AGG CGC CAT GTC AGA ACC GGC TGG -3' and p21-R: 5'-GGA AGG TAG AGC TTG GGC AGG C-3' ), p27 (p27-F: 5'-ATG TCA AAC GTG CGA GTG TCT AAC -3' and p27-R: 5'-TTA CGT TTG ACG TCT TCT GAG GCC A-3' ), c-myc (c-myc-F: 5'-ATT CTC TGC TCT CCT CGA -3' and c-myc-R: 5'-TCT TGG CAG CAG GAT AGT -3' ) with GAPDH as internal control (GAPDH-F: 5'-TCC CAT CAC CAT CTT CCA G-3' and GAPDH-R:5'ATG AGT CCT TCC ACG ATA CC3 ;). PCR cycles were adjusted to have linear amplification for all the targets. Each RT-PCR reaction was repeated at least three times. A semiquantitative analysis of mRNA levels was carried out by the "GEL DOC UV SYSTEM" (Biorad Company, CA).

\section{Western-blot analysis}

Attached cells were collected by scraping them off into a lysis buffer, and the detached cells in the supernatant were collected by centrifugation before resuspension in the lysis buffer. Protein concentration was determined by the bicinchoninic acid (BCA) method according to the manufacturer's (Pierce, Rockford, IL, U.S.A.) instructions after trichloroacetic acid precipitation. The protein lysates were mixed with equal volume of Laemmli buffer (62.5 mM Tris- $\mathrm{HCl}$ pH 6.8, 2\% SDS, 50 mM DTT, 10\% glycerol, $0.01 \%$ bromophenol blue), boiled for $3 \mathrm{~min}$ at $100^{\circ} \mathrm{C}$, and then resolved by SDS-PAGE on a 10 to $12 \%$ gel using a mini gel apparatus (Bio-Rad). Bromophenol Blue $(0.01 \%)$ was added to the samples before an equal amount of proteins was loaded in each lane for electrophoresis and blotting. The PVDF membrane was incubated with a primary antibody against $\mathrm{cdc} 2, \mathrm{cdc} 25 \mathrm{c}$ and cyclinB (Santa Cruz Biotechnology), p16 (PharMingen, San Diego, CA, U.S.A.), p21 (PharMingen, San Diego, CA, U.S.A.), p27 (PharMingen, San Diego, CA, U.S.A.), C-Myc (N-262; Santa Cruz Biotechnology, Santa Cruz, CA, U.S.A.), Acetylated histone $\mathrm{H} 3$ (AcH3) and H4 (AcH4), phospho-Histone H3 (Ser10) (Upstate Biotechnology, Lake Placid, NY), histone 3, histone 4 and GAPDH (Santa Cruz Biotechnology) for $2 \mathrm{~h}$. Signals were detected using a horseradish peroxidase-conjugated secondary antibody and an enhanced chemiluminescence detection kit (ECL; Amersham Biosciences, Pittsburgh, PA) [17] and were quantitated by an Eagle Eye II Image System with installed density-analysis software (Stratagene, La Jolla, CA, U.S.A.).

\section{Immunofluorescent Staining}

Cells were fixed with $4 \%$ paraformaldehyde in PBS for $15 \mathrm{~min}$ at room temperature for anti-acetyl histone $\mathrm{H} 4$ (06-598; Upstate Biotechnology) and anti-acetyl histone H3 (06-599; Upstate Biotechnology) staining. Cells were permeabilized with $0.2 \%$ Triton X-100 (EM Science, Gibbstown, NJ) in PBS for $10 \mathrm{~min}$ at room temperature. FITC-labeled secondary antibody (F-0382; Sigma) were applied at the concentration of 1:500. Images were taken with Nikon E800 scope. Senescence-associated heterochromatin staining was conducted as described [18].

\section{CFE in Soft Agar}

Tumor cells were resuspended in DMEM with $0.3 \%$ agar and plated in 24-well plates at 2,000 per well on top of a $0.5 \mathrm{~mL}$ precast semisolid $1 \%$ agar underlayer following treatment with Oridonin $(0,6.25,12.5,25,50$ or $100 \mu \mathrm{mol} / \mathrm{L}$ ) for 2 weeks as described previously [15]. The CFE was defined as the percentage of plated cells that formed colonies relative to an untreated control.

\section{Murine model and oridonin treatment}

Five-week-old pathogen-free athymic nude mice were purchased from Experimental Animal Centre of SIBS. (Shanghai, PR China). BALB/C nude mice were bred and maintained in a specific pathogen-free environment. Mice were allowed free access to mice standard food pellets and tapwater. Twice a week cages were cleaned and water changed. Temperature was controlled at $21^{\circ} \mathrm{C} \pm$ $2^{\circ} \mathrm{C}$. The light was on a 12 hours light-12 hour dark cycle, with light on at $8 \mathrm{am}$. Xenograft model in nude mice was established by subcutaneous inoculation of $1 \times$ $10^{6} \mathrm{SW} 1116$ cells into the right flank. The nude mice received oridonin treatment $(6.25,12.5$ or $25 \mathrm{mg} / \mathrm{kg}$ per day) when tumor was measurable. Caliper measurements of the longest perpendicular tumor diameters were performed every day to estimate the tumor volume, using the following formula: $4 \pi / 3 \times(\text { width } / 2)^{2} \times($ length $/ 2)$, representing the 3-dimensional volume of an ellipse [19]. Animals were killed when their tumors reached $2 \mathrm{~cm}$ or when the mice became moribund. TUNEL assay was performed to detect in situ apoptosis on tissue section using a DeadEnd Colorimetric TUNEL System (Promega) according to the manufacturer's instructions. Senescence-associated expression of $\beta$-galactosidase activity [20] was detected with a Senescence Detection kit (BioVision, Mountain View, CA) in situ senescence on tissue section. Animal related experiments were performed according to the Guide for the Care and Use of Laboratory Animals (NIH Publications No. 80-23, revised 1996) and approved by the committee for human treatment of animals at Shanghai Jiao Tong University School of Medicine. 


\section{Statistical Analysis}

The effects of oridonin on cell proliferation, CFE, cell cycle arrest, apoptosis, and xenograft growth in SCID mice were analyzed with two-way ANOVA and presented as the mean $\pm \mathrm{SD}$.

\section{Results}

\section{Oridonin suppresses colorectal cell proliferation}

To investigate the possible effect of oridonin on the proliferation of colorectal cancer cells, three colorectal cancer cell lines HCT116, HT29, SW1116 were used. As shown in Figure 1, oridonin could inhibit proliferation of the three colorectal cancer cells in a time- and dosedependent manner. These tumor cells showed different sensitivity to the oridonin treatment. It seemed that HT29 cells are more sensitive to oridonin treatment than HCT116 and SW1116 cells. The growth of HT29 cells was greatly inhibited by oridonin at $6.25 \mu \mathrm{M}$ for 24 hours, which become more obvious on day 3. However, $12.5 \mu \mathrm{M}$ oridonin was needed to obtain $50 \%$ inhibition in HCT1116 and SW1116 cells on day 3. At $25 \mu \mathrm{M}$, growth of all three colorectal cancer cell lines was completely inhibited.

\section{Oridonin induces cell cycle arrest and augments apoptosis}

We next examined the effects of oridonin on cell cycle distribution and apoptosis. HCT116 and SW1116 cells were treated with oridonin at low dose $(12.5 \mu \mathrm{M}$ for HCT116 or $25 \mu \mathrm{M}$ for SW1116) or at higher dose (25 $\mu \mathrm{M}$ for HCT116 or $50 \mu \mathrm{M}$ for SW1116) for 24 hours. Low dose oridonin causes obvious G2/M arrest in HCT116 and SW1116 cells. As shown in Figure 2A and $2 \mathrm{~B}$, the population of $\mathrm{G} 2 / \mathrm{M}$ cells increased from $23.5 \%$ and $18.2 \%$ to $44.1 \%$ and $39.6 \%$, respectively in HCT 116 and SW1116 cells. Further, the G2/M related protein

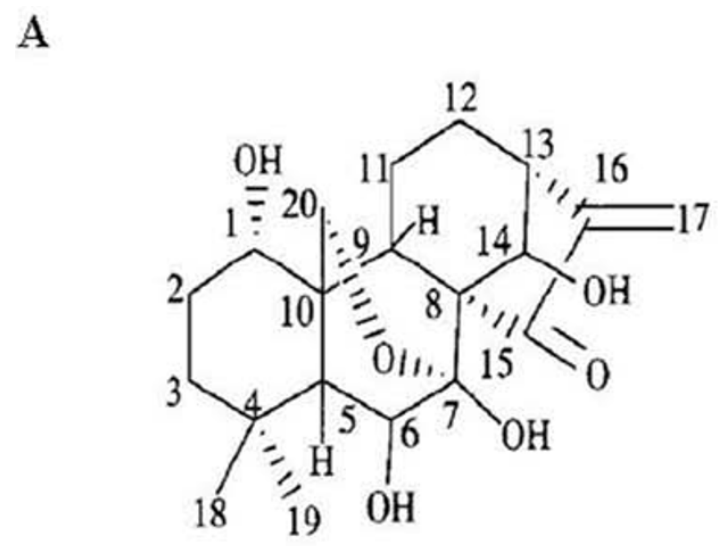

$\mathrm{C}$

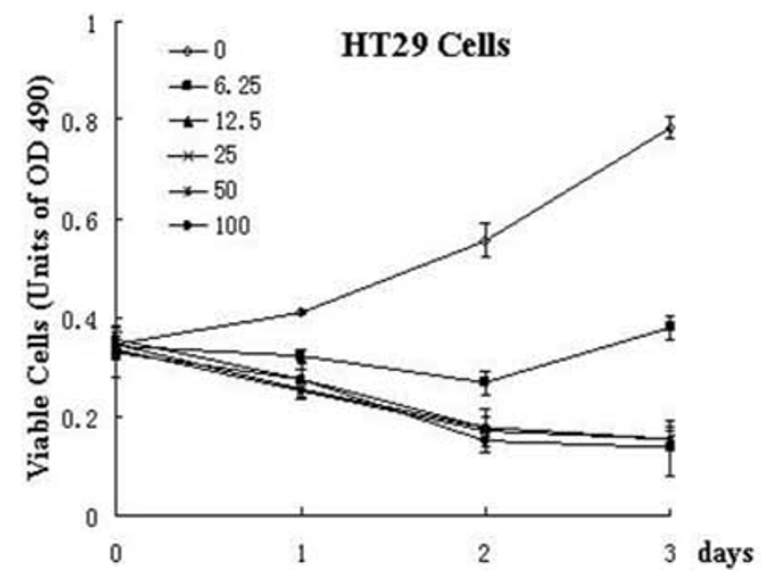

B

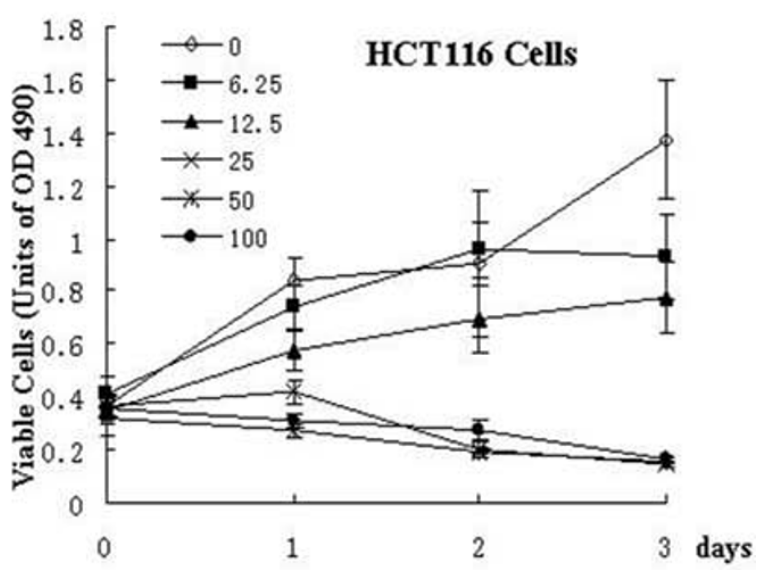

D

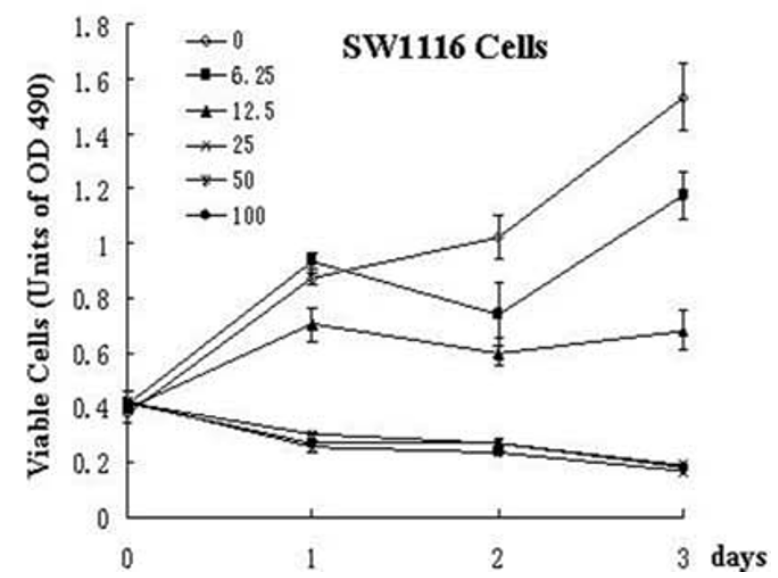

Figure 1 Oridonin inhibits cell proliferation of colorectal cancer cells. (A) Chemical structure of oridonin. (B), (C) and (D) HCT116, HT29 and SW1116 cells were treated with $0,6.25,12.5,25,50100 \mu \mathrm{M}$ oridonin for 1, 2 and 3 days. Effects of oridonin on cell proliferation were determined by using a CCK-8 Kit. Error bars represent SD of experiments. 


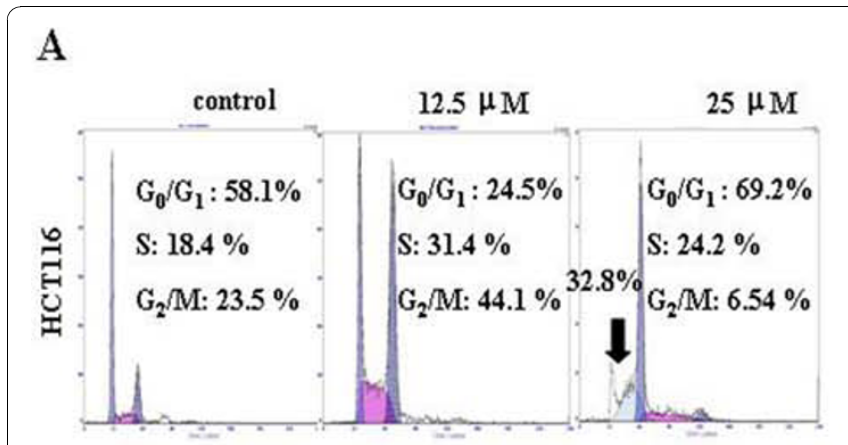

B
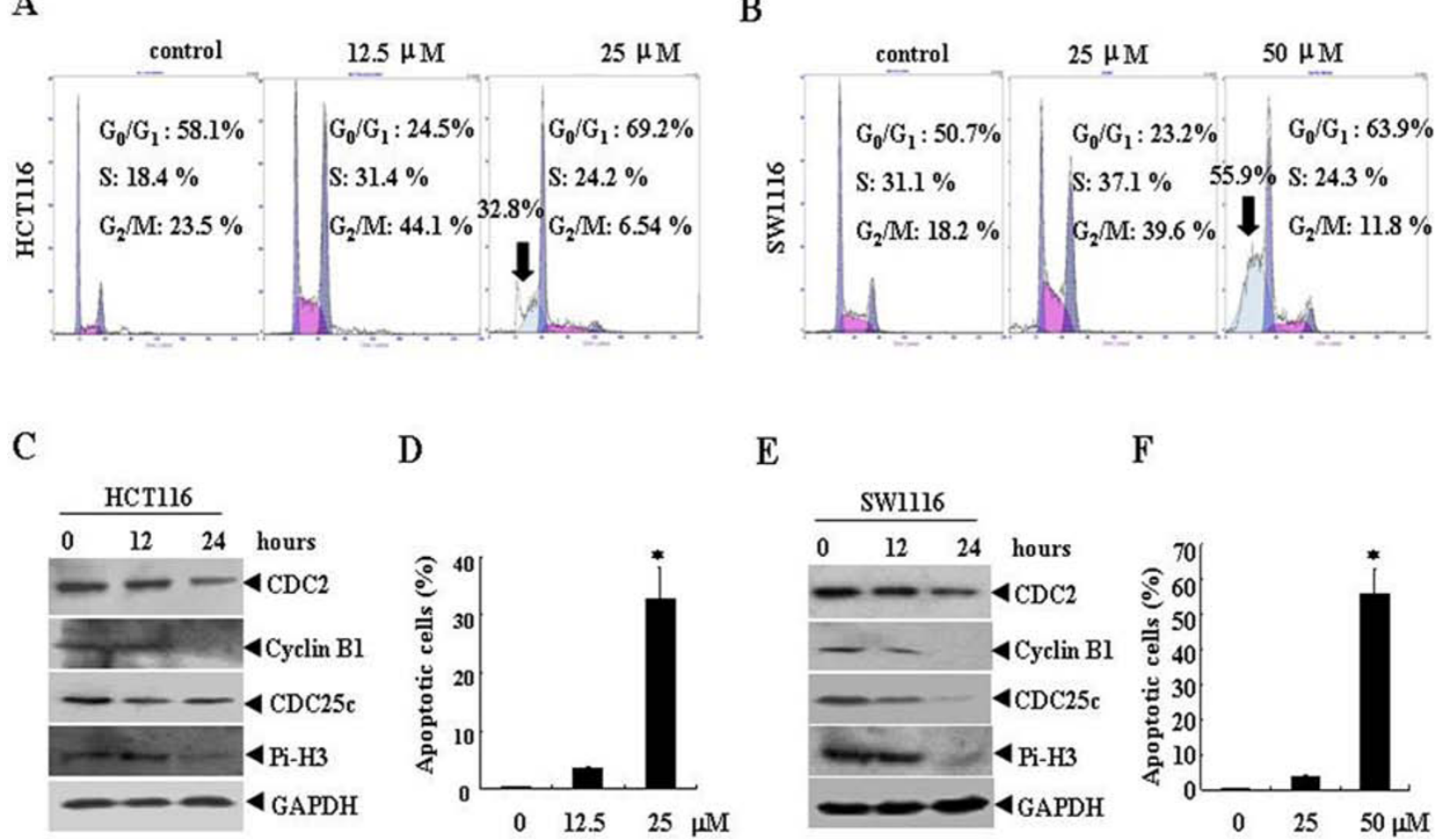

E

F
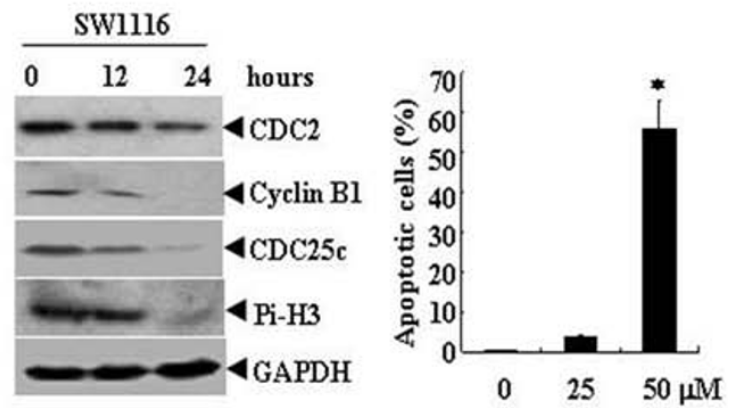

Figure 2 Oridonin induces cell cycle arrest and apoptosis. HCT116 and SW1116 cells were treated with 0, 12.5, 25 or $50 \mu \mathrm{M}$ Oridonin for 24 hours. Cell cycle distribution was determined by flow cytometry and the representative graphs are shown in (A) and (B). Apoptosis was examined by analyzing subdiploid population ( $\mathrm{A}$ and $\mathrm{B}$, black arrow) and terminal deoxynucleotidyl transferase-mediated dUTP nick end labeling assay ( $D$ and $F)$, in which at least 1,000 cells from randomly selected high-power fields were counted. Symbol * represents $P<0.05$ compared with control group. The indicated proteins were detected by western blot (C and $\mathrm{E})$.

cyclin $\mathrm{B}, \mathrm{cdc} 2$, cdc25c and phosphorylated histone $\mathrm{H} 3$ were detected in HCT116 and SW1116 cells (Figure 2C and $2 \mathrm{E}$ ). Oridonin treatment for $12,24 \mathrm{~h}$ causes downregulation of all these proteins, indicating that oridonin induces G2 arrest in these cells.

While at higher concentration $(25 \mu \mathrm{M}$ for HCT116 or $50 \mu \mathrm{M}$ for SW1116), a marked increase of subdiploid peak was observed, indicating the increase of apoptotic cells. This apoptosis inducing effect of oridonin was further confirmed by the terminal deoxynucleotidyl transferase-mediated dUTP nick end labeling assay (Figure $2 \mathrm{D}$ and $2 \mathrm{~F}$ ). These results suggested cell cycle arrest and apoptosis induction involved in oridonin induced cell proliferation inhibition.

\section{Oridonin induces cellular senescence}

Cellular senescence has been identified as one of the mechanisms mediating the anticancer effects of chemotherapies [16]. One of the morphologic changes that were frequently observed in the oridonin-treated cells is the flattening of the adherent cells with increased granularity, which is a typical morphologic change associated with cellular senescence (Figure $3 \mathrm{~A}$ and $3 \mathrm{C}$ ). By examining senescence-associated expression of $\beta$-galactosidase activity, we confirmed that cellular senescence was indeed induced in those flattened HCT116 and SW1116 cells treated by oridonin $(12.5$ or $25 \mu \mathrm{M})$ for three days (Figure 3B and 3D), indicating that senescence inducing also contribute to the proliferation inhibition effect of oridonin.

\section{Oridonin activates p21, p16 and p27 expression and down-regulates the expression of oncogene c-myc}

To perform detailed temporal analysis of gene expression alteration, SW1116 cells were treated with $25 \mu \mathrm{M}$ oridonin for $0,24,48$ and 72 hours. Then, the mRNA and protein levels of p16, p21, p27 were examined. As shown in Figure 4A and 4C, after treated oridonin for 24 hours, the mRNA and protein level of p21 but not p16 and p27 were significantly increased. Treatment with oridonin for 48 and 72 hours resulted in increase of the p16, p21 and p27. A series of studies have documented that $\mathrm{c}$-myc regulates a wide range of genes involved in cell proliferation, differentiation, and apoptosis [21]. We also detected the expression of c-myc in oridonin treated SW1116 cells. Treatment with oridonin 


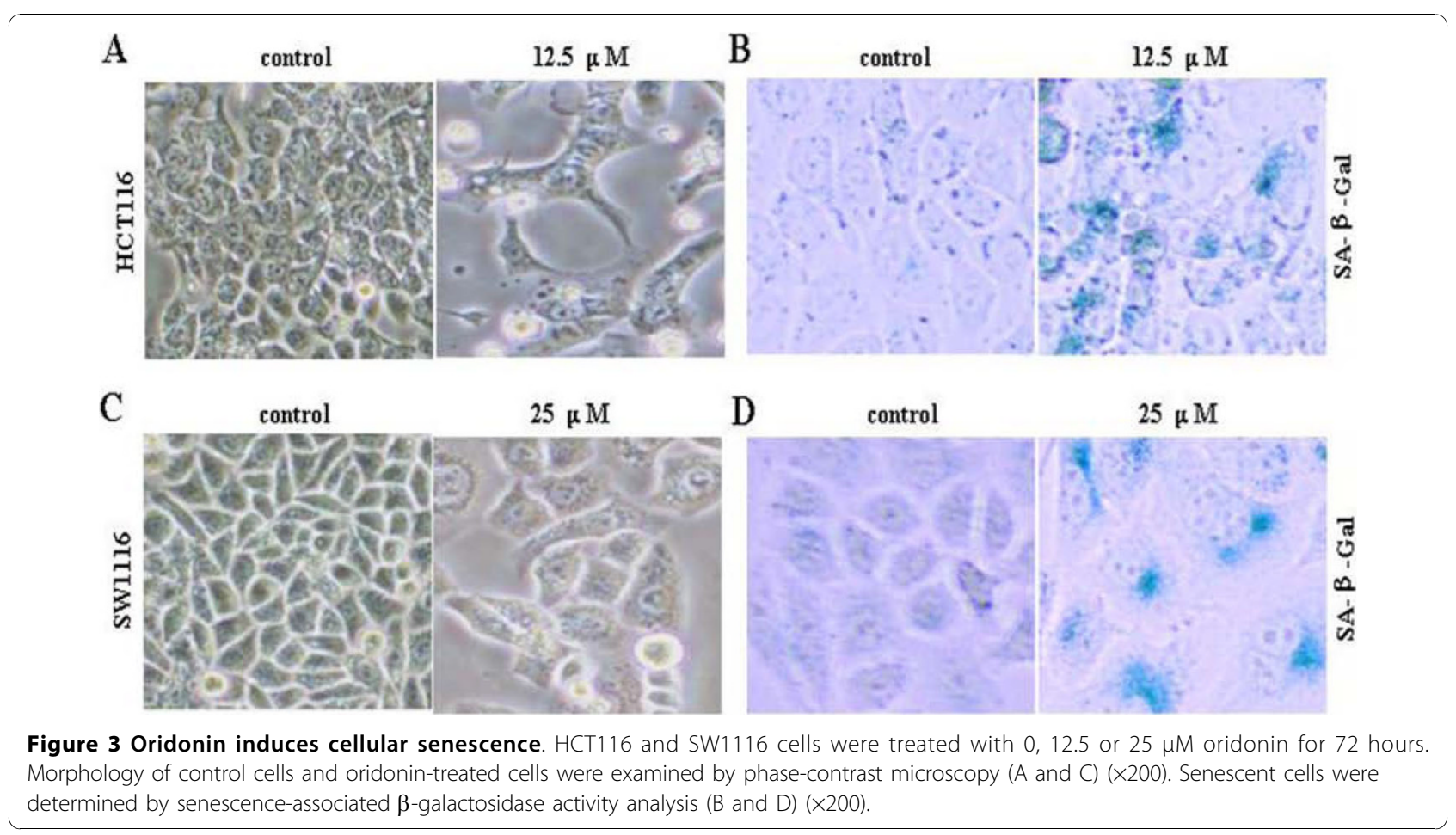

A

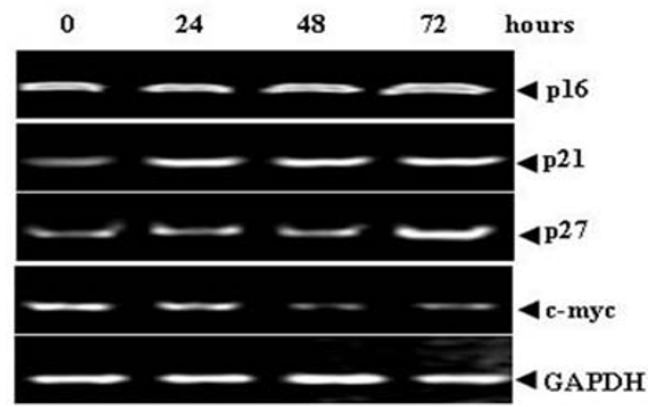

B

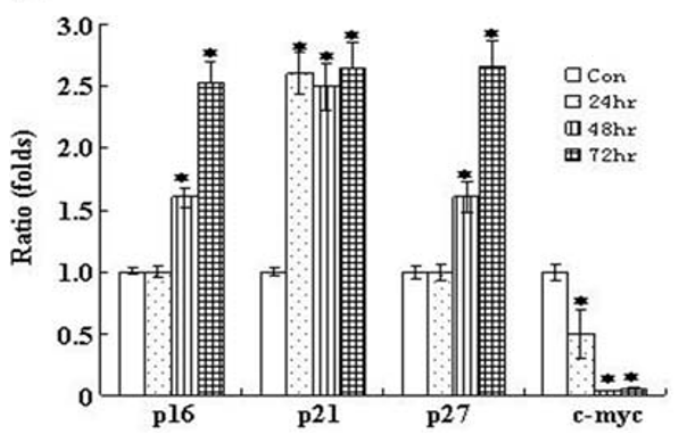

C

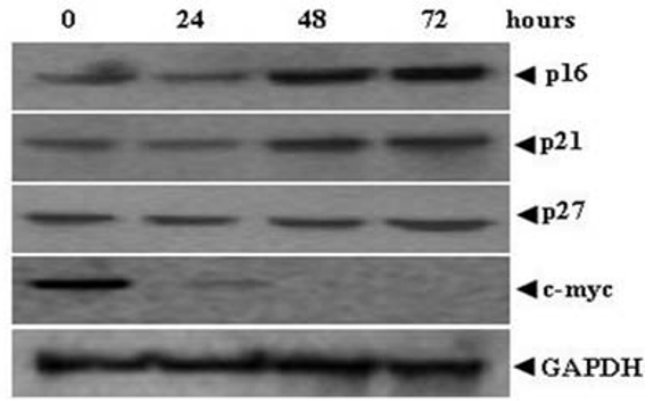

D

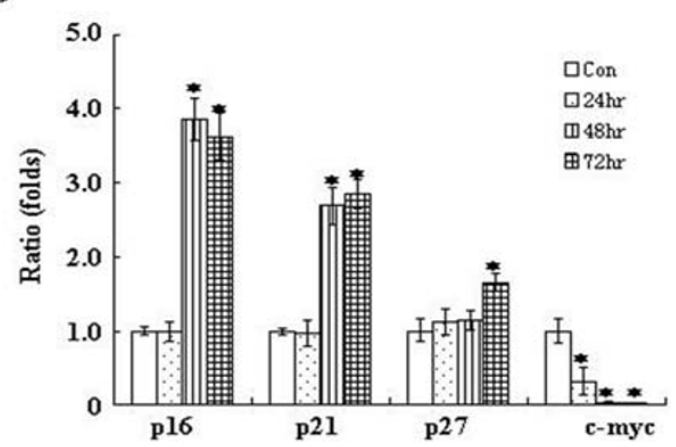

Figure 4 Oridonin regulates the expression of p21, p16, p27 and c-myc in vitro. SW1116 cells were treated with $25 \mu \mathrm{M}$ Oridonin for 0,24 , 48 and 72 hours. Semi-quantitative RT-PCR was used to examine the changes of mRNA of p16, p21, p27 and c-myc (A). (B) The graph shows densitometric analyses of the p16, p21, p27 or c-myc/GAPDH the ratios from (A). The concomitant changes of protein expression were analyzed with Western blot (C). (D) The graph shows densitometric analysis of the p16, p21, p27 or c-myc relative to GAPDH. Symbol * represents P < 0.05 compared with control group. 
$(25 \mu \mathrm{M})$ dramatically reduced c-myc mRNA transcription and c-myc protein levels as early as 24 hours. These data suggested that suppression of c-myc and upregulation of p16, p21 and p27 correlated with oridonin responsiveness of colorectal cancer cells.

\section{Oridonin induces global changes in chromatin structure}

Cellular senescence is known to be associated with changes in chromatin structure $[18,22]$. Therefore, we examined global chromatin modifications associated with cellular senescence in SW1116 cell lines treated with oridonin $(25 \mu \mathrm{M})$ for 3 days in vitro. As shown in Figure $5 \mathrm{~A}$, after $72 \mathrm{~h}$ of oridonin treatment, heterochromatin formation were observed with DAPI staining, and a marked global increase of total acetylation of histone $\mathrm{H} 3$ and histone $\mathrm{H} 4$ were detected by immunofluorescence.
Time course analysis showed that protein levels of acetylation of histone $\mathrm{H} 3$ and histone $\mathrm{H} 4$ gradually increased, especially for histone $\mathrm{H} 4$ (Figure $5 \mathrm{~B}$ and $5 \mathrm{C}$ ). Hence, oridonin treatment resulted in global changes of histone modifications that have been associated with cellular senescence.

\section{Oridonin Suppresses CFE}

To examine the suppressive effects of oridonin on CFE, SW1116 cells were treated with $0,6.25,12.5,25,50,100$ $\mu \mathrm{M}$ oridonin for 14 days. Our results showed that oridonin exerted dose-dependant suppression of CFE in SW1116 cells $(\mathrm{P}<0.01$; Figure $6 \mathrm{~A})$. Treatment with $6.25 \mu \mathrm{M}$ oridonin for 2 week causes over $50 \%$ inhibition of CFE. With the increase in drug concentration, more significant suppressive effects were observed. At higher
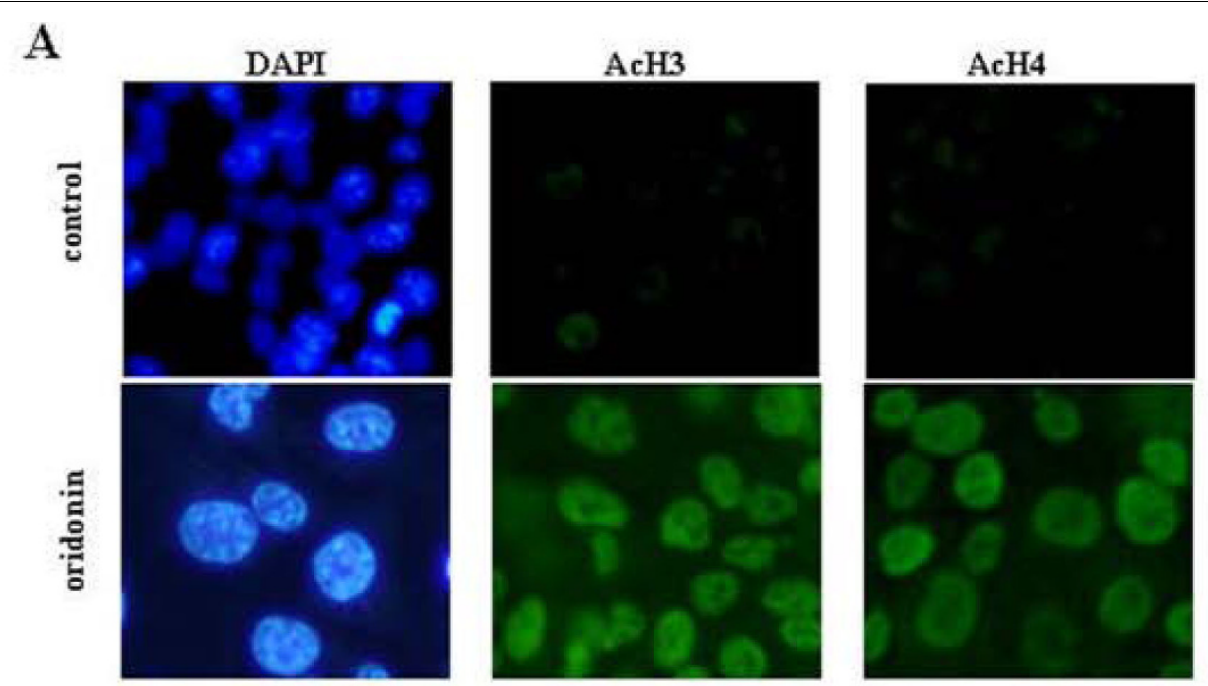

B
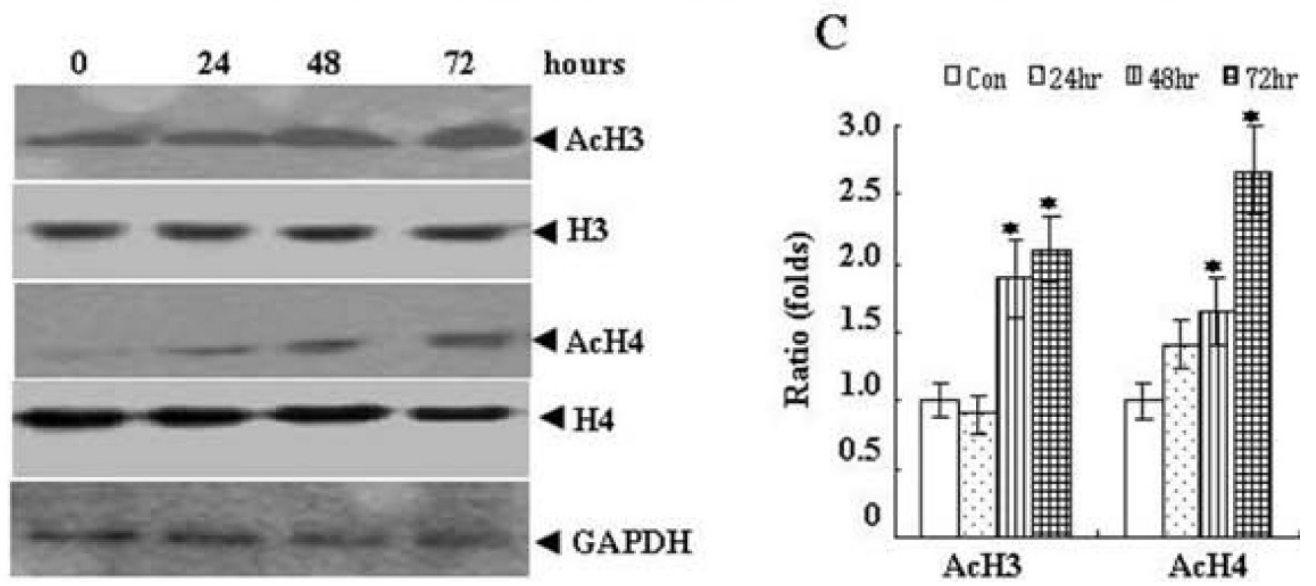

Figure 5 Induction of hyperacetylated histone $\mathrm{H}_{3}(\mathrm{AcH} 3)$ and $\mathbf{H} 4 \mathbf{4}(\mathbf{A c H} 4)$ during the treatment with oridonin. SW1116 cells were treated with $25 \mu \mathrm{M}$ oridonin for 72 hours. (A) Heterochromatin formation was shown by DAPI staining. Distribution of AcH3 and AcH4 were examined by immunofluorescence staining with the indicated antibodies (×200). (B) Protein levels of AcH3 and AcH4 were detected by Western blots with the indicated antibodies. H3, H4 and GAPDH were used as loading control. (C) The graph shows densitometric analysis of the expression of $\mathrm{AcH} 3$ and $\mathrm{AcH} 4$ relative to GAPDH. Symbol * represents $\mathrm{P}<0.05$ compared with control group. 

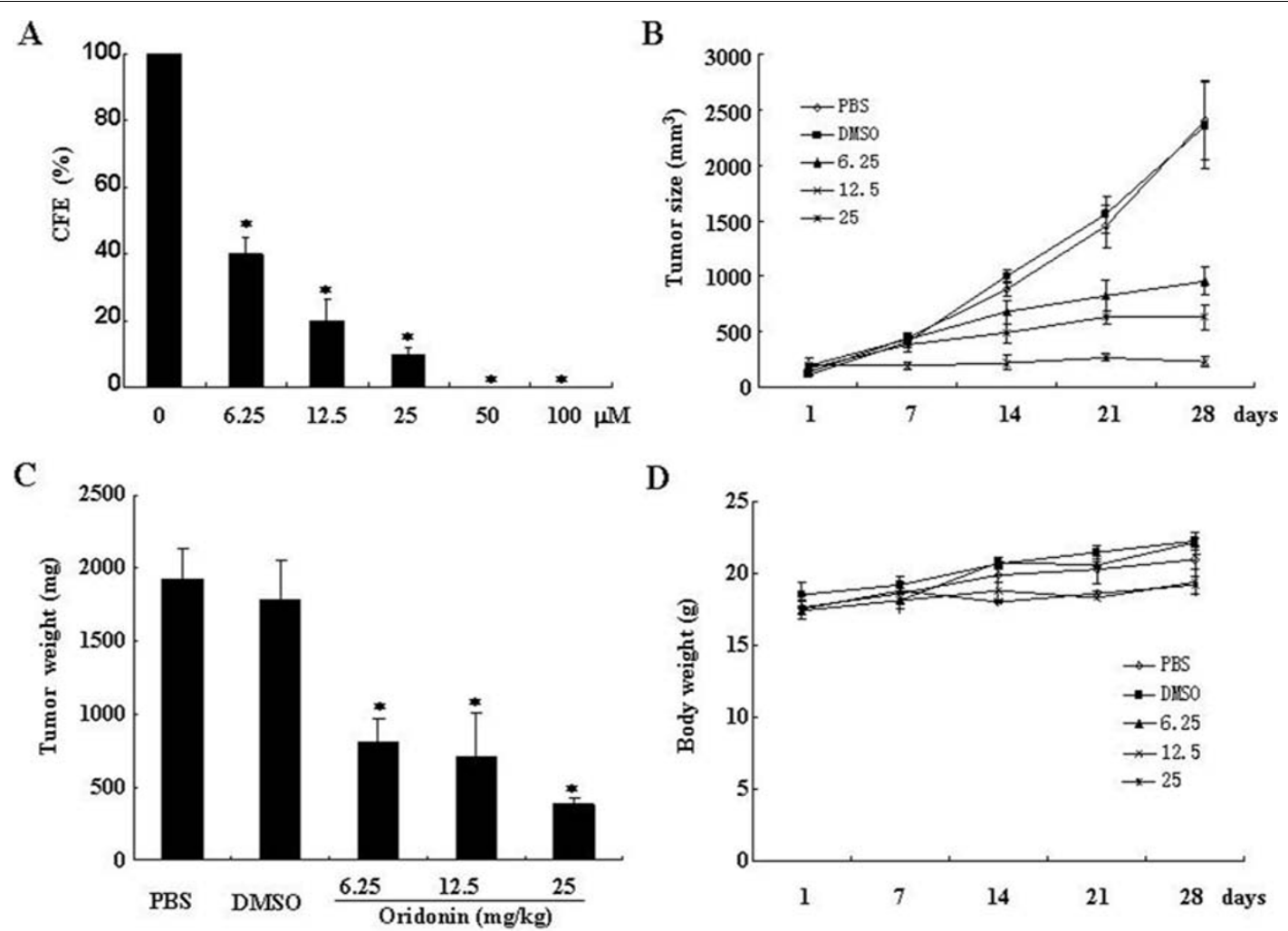

Figure 6 Oridonin inhibits colony formation of SW1116 in vitro and tumor growth in vivo. SW1116 cells were treated with 0, 6.25, 12.5, 25, 50, $100 \mu \mathrm{M}$ oridonin for 14 days. (A) The CFE was defined as the percentage of plated cells that formed colonies relative to an untreated control (untreated cells $=100 \%$ ). The means \pm standard deviations of six independent experiments per oridonin concentration are shown. The symbol * represents $P<0.05$ compared with control group. SW1116 cells $\left(1 \times 10^{7}\right.$ cells in $100 \mu$ l of PBS $)$ were subcutaneously injected into the right flank of BALB/c nude mice. The mice were then administered intraperitoneally with $0.2 \mathrm{ml}$ of PBS or DMSO (1\% in PBS) or Oridonin (6.25, 12.5 and $25 \mathrm{mg} / \mathrm{kg}$ respectively) daily when tumors reached a volume of $50-100 \mathrm{~mm}^{3}$. (B) Tumor dimension was periodically measured using calipers over a 4-week period. Each point represents average volume calculated from ten mice. (C) One day after the last treatment, tumors were excised from the animals, and tumor weight was measured. The data are representative of three independent experiments. Symbol * represents $\mathrm{P}<0.05$ compared with control group. (D) Changes in body weight of mice treated with PBS or DMSO (1\% in PBS) or oridonin.

concentration (50 and $100 \mu \mathrm{M})$, the formation of colony was completely inhibited (Figure 6A).

\section{Oridonin Suppresses the Growth of SW1116 Xenografts in $B A L B / C$ nude mice}

We next further assessed the in vivo anti-colorectal cancer effects of oridonin. BALB/C nude mice xenografts were treated with oridonin by daily i.p injection at 6.25 or 12.5 or $25 \mathrm{mg} / \mathrm{kg}$ for up to 28 days. Such treatment resulted in significant suppression of xenograft growth, compared with the PBS or DMSO (1\% in PBS) treated group $(\mathrm{P}<0.05$; Figure $6 \mathrm{~B}$ and $6 \mathrm{C})$. In the low-dose $(6.25 \mathrm{mg} / \mathrm{kg})$ group, significant tumor growth inhibition effect was observed until 21 days, while in the middle dose $(12.5 \mathrm{mg} / \mathrm{kg})$ group, significant tumor growth inhibition effect was observed on day 14. More interesting, the high dose $(25 \mathrm{mg} / \mathrm{kg})$ administration almost completely inhibited tumor growth at the onset phase. It is worth noting that no obvious changes in body weight were observed in the oridonin treated groups, compared with the PBS or DMSO (1\% in PBS) treated groups (Figure 6D). In $\mathrm{H} \& \mathrm{E}$ stained tumor section, sparse tumor cells and areas of necrosis foci can be seen in oridonin treated mice, while massive tumor cells were observed in PBS or DMSO (1\% in PBS) treated mice (Figure 7A). TUNEL assay (Figure 7B) and Senescence-associated- $\beta$ galactosidase (SA- $\beta$-Gal) staining (Figure $7 \mathrm{C}$ ) were also performed to detect the degree of apoptosis and senescence. The results showed that oridonin induces apoptosis and senescence of colorectal cells in vivo in a dose dependent manner.

\section{Discussion}

Chemotherapy remains the primary treatment for systemic malignancies. It is now clear that drug-induced damage is not invariably lethal, but can instead initiate a series of post-damage responses including apoptosis, mitotic catastrophe, and cellular senescence $[23,24]$. 


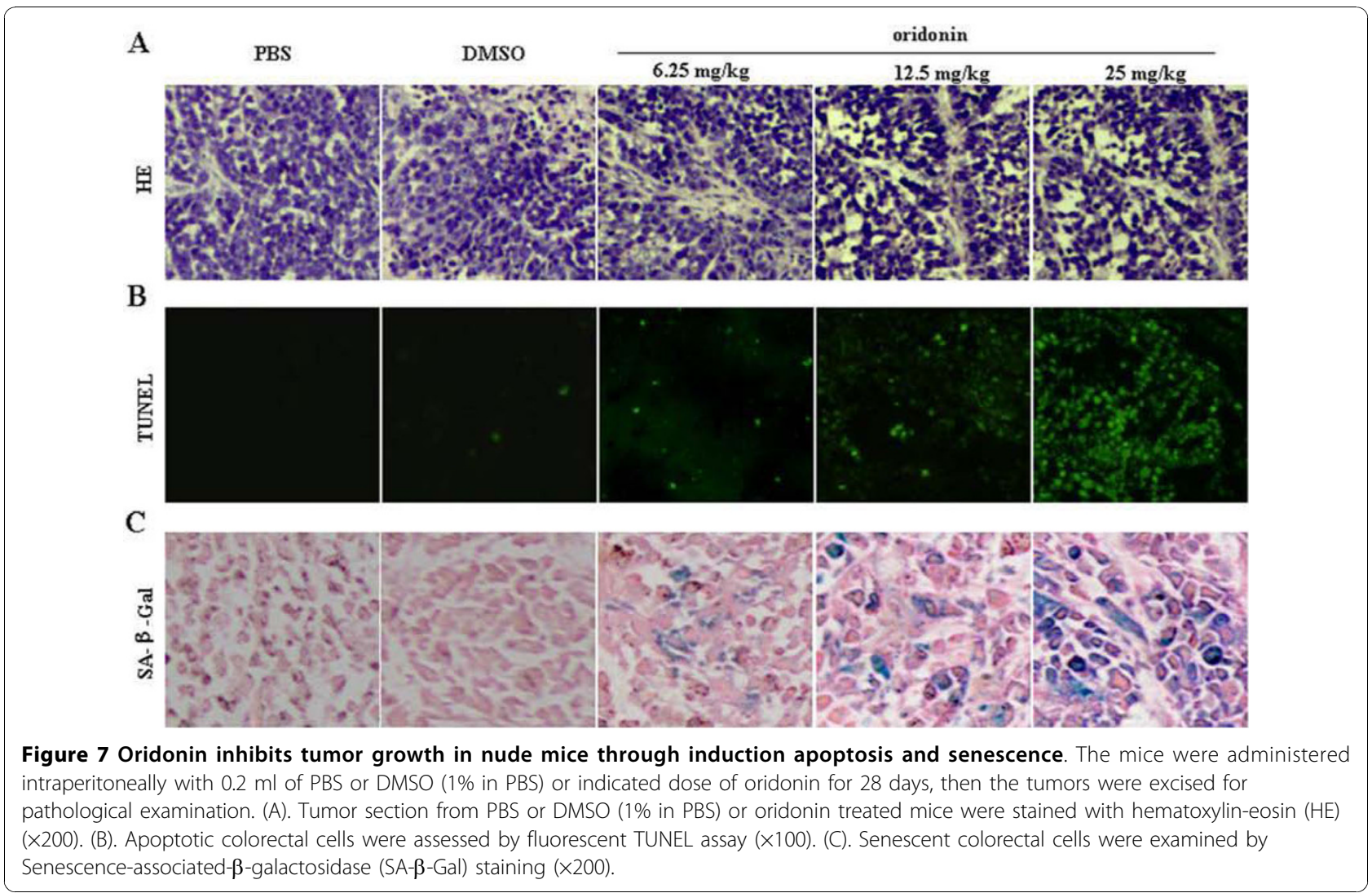

Therefore, the integrity of these damage responses might also influence treatment sensitivity. In the current study, we showed that the potent anti-cancer activities of oridonin in colorectal cancer are correlated with induction of apoptosis, cell-cycle arrest and cellular senescence.

Oridonin treatment resulted in significant growth arrest in colorectal cancer cells and this in vitro effect was time and concentration dependent. This finding is in agreement with our previous results with oridonin in acute promyelocytic leukemia cells and others [14]. More importantly, we further showed that oridonin possesses strong inhibitory activities on tumorigenicity of colorectal cancer cells. Oridonin at $6.25 \mu \mathrm{M}$ could inhibit the colony-forming by $50 \%$. With the increase in drug concentration, the formation of colony was almost completely inhibited. In consistent with these results in vitro, treatment with $6.25 \mathrm{mg} / \mathrm{kg}$ oridonin in SW1116 xenografts $\mathrm{BALB} / \mathrm{C}$ nude mice for 4 weeks was able to significantly decrease the growth of xenografts. These results provided strong evidence to support the notion that oridonin has strong activity against colorectal cancer.

Apoptosis is a well-characterized post-damage program and diverse anticancer agents can induce apoptosis through common pathways [24]. It has been reported previously that the antitumor effect of oridonin was due to its apoptosis induction activity [14,25-28]. In agreement with these reports, our data showed oridonin could induce apoptosis of colorectal cancer cells in vitro and in vivo. In addition to apoptosis induction, we found that oridonin could induce senescence of colorectal cancer cells. In fibroblasts and epithelial cells, senescence is controlled by the p53 and Rb tumor suppressor pathways, although the contribution of each pathway to the program depends on species and cell type [20]. Here, oridonin-induced arrest was accompanied by substantial increases in p21, p16 (an Rb regulator linked exclusively to senescence) and SA- $\beta$-gal activity. It is interesting to note that oridonin-induced senescence associated with G2 arrest. In most cases, the senescence is associated with $\mathrm{G} 1 / \mathrm{G} 0$ arrest. However, many reports also showed that $\mathrm{G} 2 / \mathrm{M}$ arrest is associated with senescence [29-32]. For example, some drugs including DNA damage agent Adriamycin, DNA methylating agent Temozolomide, HDAC inhibitor sodium butyrate could induce G2/M arrest and senescence-like phenotype via p21 induction. Similar to these results, oridonin could also up-regulate the expression of p21, p27 and p16, which may contribute to the observed senescent phenotype.

The expression of cyclin-dependent kinase inhibitor p21 and p27 has been implicated in chemotherapyinduced cell cycle arrest in numerous human cancers 
[33,34]. In this study, we confirmed that oridonin is capable of activating p21 and p27 gene in colorectal cancer cells. Overexpression of c-myc had been frequently detected in colorectal cancer and is associated with shorter survival and tumor anaplasia [35-37]. C-myc has also been reported to promote cell cycle reentry and proliferation through repression of p21 and p27 expression [38]. Therefore, the suppression of c-myc expression by oridonin may render substantial therapeutic benefits in colorectal cancer patients by inhibiting the driving activities of c-myc in cell proliferation and cell cycle progression. In line with previous reports, our data showed oridonin- induced p21 and p27 and down-regulated c-myc in vitro.

Epigenetic changes are tightly related to neoplastic transformation in colorectal cancers. Histone modifications, recently recognized as a 'histone code' that affects chromatin structure and gene expression also play an important role in the establishment of gene silencing during tumorigenesis. Alterations in histone modifications appear to be primary mediators of epigenetic inheritance in cancer cells [39-41]. The potential reversibility of epigenetic states in the tumor cell is an attractive target for cancer therapy [42]. Our data showed oridonin induced histone ( $\mathrm{H} 3$ and $\mathrm{H} 4)$ hyperacetylation in vitro. We also found that the levels of accumulated $\mathrm{AcH} 3$ and $\mathrm{AcH} 4$ correlated with the degree of in vitro growth suppression in the oridonin-sensitive colorectal cancer cell lines, suggesting that the anti-colorectal cancer effects of oridonin were at least partly mediated through histone $\mathrm{H} 3$ and $\mathrm{H} 4$ hyperacetylation.

\section{Conclusions}

In summary, we showed that oridonin possesses potent in vitro and in vivo anti-colorectal cancer activities by suppressing cell proliferation, promoting apoptosis, inducing cell cycle arrest and cellular senescence. These results may lay the groundwork for further studies using specific genetically engineered models to establish the causal relationship between oridonin antitumor activity and specific genetic pathways and to identify molecular markers that will predict drug responsiveness and guide the development of future clinical therapies.

\footnotetext{
Acknowledgements

This work was supported in part by the National Natural Science Foundation of China $(81070433,91013008)$, Science and Technology Committee of Shanghai (08JC1413400), Science and Technology Committee of Baoshan District (08-E-13), Renji hospital and college of basic medicine cooperation foundation (ZD0704) and NO.3 People's Hospital affiliated to Shanghai JiaoTong University School of Medicine (syz07-04).
}

\section{Author details}

'NO.3 People's Hospital affiliated to Shanghai Jiao-Tong University School of Medicine (SJTU-SM), Shanghai 201900, PR China. ${ }^{2}$ Dept. of Pathophysiology, Key Laboratory of Cell Differentiation and Apoptosis of National Ministry of
Education, Shanghai Jiao-Tong University School of Medicine (SJTU-SM), Shanghai 200025, PR China. 'Zhejiang Provincial Key Laboratory of Medical Genetics, School of Life Sciences, Wenzhou Medical College, Wenzhou, Zhejiang, PR China. ${ }^{4}$ Department of Gastroenterology, The tenth Hospital Affiliated to Tongji University, Shanghai, PR China. ${ }^{5}$ Renji Hospital affiliated to Shanghai Jiao-Tong University School of Medicine (SJTU-SM), Shanghai 201900, PR China.

\section{Authors' contributions}

F-HG and $\mathrm{X}-\mathrm{HH}$ carried out the data collection and data analysis, and drafted the manuscript. WL, HL and Y-JZ participated in the design of the study, performed the statistical analysis and participated in the interpretation of data. Z-YG, M-HX and S-TW participated in the design of the study and the acquisition and interpretation of data. BJ, FL, Y-ZZ, YF and F-YC were involved in the interpretation of data and critically revised the manuscript. $Y$ LW conceived the study, participated in its design and coordination, and helped in statistical analysis and drafting of the manuscript. All authors have read and approved the final manuscript.

\section{Competing interests}

The authors declare that they have no competing interests.

Received: 27 November 2009 Accepted: 6 November 2010 Published: 6 November 2010

\section{References}

1. Boursi B, Arber N: Current and future clinical strategies in colon cancer prevention and the emerging role of chemoprevention. Curr Pharm Des 2007, 13(22):2274-2282.

2. Mayo SC, Pawlik TM: Current management of colorectal hepatic metastasis. Expert Rev Gastroenterol Hepatol 2009, 3(2):131-144.

3. Hebbar M, Ychou M, Ducreux M: Current place of high-dose irinotecan chemotherapy in patients with metastatic colorectal cancer. J Cancer Res Clin Oncol 2009, 135(6):749-752.

4. Berri RN, Abdalla EK: Curable metastatic colorectal cancer: recommended paradigms. Curr Oncol Rep 2009, 11(3):200-208.

5. Mihaylova Z, Raynov J: Neoadjuvant chemotherapy and targeted therapy in patients with liver metastases from colorectal cancer; medical oncologist's point of view. J BUON 2008, 13(3):323-331.

6. McGarvey DJ, Croteau R: Terpenoid metabolism. Plant Cell 1995, 7(7):1015-1026.

7. Salminen A, Lehtonen M, Suuronen T, Kaarniranta K, Huuskonen J: Terpenoids: natural inhibitors of NF-kappaB signaling with antiinflammatory and anticancer potential. Cell Mol Life Sci 2008, 65(19):2979-2999.

8. Wang X, Wei Y, Yuan S, Liu G, Lu Y, Zhang J, Wang W: Potential anticancer activity of tanshinone IIA against human breast cancer. Int J Cancer 2005, 116(5):799-807.

9. Nizamutdinova IT, Lee GW, Son KH, Jeon SJ, Kang SS, Kim YS, Lee JH, Seo HG, Chang KC, Kim HJ: Tanshinone I effectively induces apoptosis in estrogen receptor-positive (MCF-7) and estrogen receptor-negative (MDA-MB-231) breast cancer cells. Int J Oncol 2008, 33(3):485-491.

10. Sethi G, Ahn KS, Pandey MK, Aggarwal BB: Celastrol, a novel triterpene, potentiates TNF-induced apoptosis and suppresses invasion of tumor cells by inhibiting NF-kappaB-regulated gene products and TAK1mediated NF-kappaB activation. Blood 2007, 109(7):2727-2735.

11. Hsieh TC, Wijeratne EK, Liang JY, Gunatilaka AL, Wu JM: Differential control of growth, cell cycle progression, and expression of NF-kappaB in human breast cancer cells MCF-7, MCF-10A, and MDA-MB-231 by ponicidin and oridonin, diterpenoids from the chinese herb Rabdosia rubescens. Biochem Biophys Res Commun 2005, 337(1):224-231.

12. Ikezoe T, Yang Y, Bandobashi K, Saito T, Takemoto S, Machida H, Togitani K, Koeffler HP, Taguchi H: Oridonin, a diterpenoid purified from Rabdosia rubescens, inhibits the proliferation of cells from lymphoid malignancies in association with blockade of the NF-kappa B signal pathways. $\mathrm{Mol}$ Cancer Ther 2005, 4(4):578-586.

13. Liu J, Yang F, Zhang Y, Li J: Studies on the cell-immunosuppressive mechanism of Oridonin from Isodon serra. Int Immunopharmacol 2007, 7(7):945-954.

14. Gao F, Tang Q, Yang P, Fang Y, Li W, Wu Y: Apoptosis inducing and differentiation enhancement effect of oridonin on the all-trans-retinoic 
acid-sensitive and -resistant acute promyelocytic leukemia cells. Int I Lab Hematol 2010, 32(1 Pt 1):e114-122.

15. Li XN, Parikh S, Shu Q, Jung HL, Chow CW, Perlaky L, Leung HC, Su J, Blaney S, Lau CC: Phenylbutyrate and phenylacetate induce differentiation and inhibit proliferation of human medulloblastoma cells. Clin Cancer Res 2004, 10(3):1150-1159.

16. Schmitt CA: Senescence, apoptosis and therapy-cutting the lifelines of cancer. Nat Rev Cancer 2003, 3(4):286-295.

17. Gao FH, Wang Q, Wu YL, Li X, Zhao KW, Chen GQ: c-Jun N-terminal kinase mediates AML1-ETO protein-induced connexin-43 expression. Biochem Biophys Res Commun 2007, 356(2):505-511.

18. Narita M, Nunez S, Heard E, Lin AW, Hearn SA, Spector DL, Hannon GJ, Lowe SW: Rb-mediated heterochromatin formation and silencing of E2F target genes during cellular senescence. Cell 2003, 113(6):703-716.

19. LeBlanc R, Catley LP, Hideshima T, Lentzsch S, Mitsiades CS, Mitsiades N, Neuberg D, Goloubeva O, Pien CS, Adams J, et al: Proteasome inhibitor PS-341 inhibits human myeloma cell growth in vivo and prolongs survival in a murine model. Cancer Res 2002, 62(17):4996-5000.

20. Schmitt CA, Fridman JS, Yang M, Lee S, Baranov E, Hoffman RM, Lowe SW: A senescence program controlled by $\mathrm{p} 53$ and p16INK4a contributes to the outcome of cancer therapy. Cell 2002, 109(3):335-346.

21. Wong SC, Chan JK, Lee KC, Hsiao WL: Differential expression of p16/p21/ p27 and cyclin D1/D3, and their relationships to cell proliferation, apoptosis, and tumour progression in invasive ductal carcinoma of the breast. J Pathol 2001, 194(1):35-42.

22. Zhang R, Poustovoitov MV, Ye X, Santos HA, Chen W, Daganzo SM, Erzberger JP, Serebriiskii IG, Canutescu AA, Dunbrack RL, et al: Formation of MacroH2A-containing senescence-associated heterochromatin foci and senescence driven by ASF1a and HIRA. Dev Cell 2005, 8(1):19-30.

23. Chang BD, Broude EV, Dokmanovic M, Zhu H, Ruth A, Xuan Y, Kandel ES, Lausch E, Christov K, Roninson IB: A senescence-like phenotype distinguishes tumor cells that undergo terminal proliferation arrest after exposure to anticancer agents. Cancer Res 1999, 59(15):3761-3767.

24. Johnstone RW, Ruefli AA, Lowe SW: Apoptosis: a link between cancer genetics and chemotherapy. Cell 2002, 108(2):153-164.

25. Huang J, Wu L, Tashiro S, Onodera S, Ikejima T: Reactive oxygen species mediate oridonin-induced HepG2 apoptosis through p53, MAPK, and mitochondrial signaling pathways. J Pharmacol Sci 2008, 107(4):370-379.

26. Jin S, Shen JN, Wang J, Huang G, Zhou JG: Oridonin induced apoptosis through Akt and MAPKs signaling pathways in human osteosarcoma cells. Cancer Biol Ther 2007, 6(2):261-268.

27. Zhou GB, Kang H, Wang L, Gao L, Liu P, Xie J, Zhang FX, Weng XQ, Shen ZX, Chen J, et al: Oridonin, a diterpenoid extracted from medicinal herbs, targets AML1-ETO fusion protein and shows potent antitumor activity with low adverse effects on $\mathrm{t}(8 ; 21)$ leukemia in vitro and in vivo. Blood 2007, 109(8):3441-3450.

28. Cheng Y, Qiu F, Ye YC, Tashiro S, Onodera S, Ikejima T: Oridonin induces G2/M arrest and apoptosis via activating ERK-p53 apoptotic pathway and inhibiting PTK-Ras-Raf-JNK survival pathway in murine fibrosarcoma L929 cells. Arch Biochem Biophys 2009, 490(1):70-75.

29. Hirose $Y$, Berger MS, Pieper RO: p53 effects both the duration of G2/M arrest and the fate of temozolomide-treated human glioblastoma cells. Cancer Res 2001, 61(5):1957-1963.

30. Shay JW, Roninson IB: Hallmarks of senescence in carcinogenesis and cancer therapy. Oncogene 2004, 23(16):2919-2933.

31. Terao Y, Nishida J, Horiuchi S, Rong F, Ueoka Y, Matsuda T, Kato H, Furugen Y, Yoshida K, Kato K, et al: Sodium butyrate induces growth arrest and senescence-like phenotypes in gynecologic cancer cells. Int $J$ Cancer 2001, 94(2):257-267.

32. Vigneron A, Roninson IB, Gamelin E, Coqueret O: Src inhibits adriamycininduced senescence and G2 checkpoint arrest by blocking the induction of p21waf1. Cancer Res 2005, 65(19):8927-8935.

33. Shankar S, Singh G, Srivastava RK: Chemoprevention by resveratrol: molecular mechanisms and therapeutic potential. Front Biosci 2007, 12:4839-4854.

34. Lee JT, Lehmann BD, Terrian DM, Chappell WH, Stivala F, Libra M, Martelli AM, Steelman LS, McCubrey JA: Targeting prostate cancer based on signal transduction and cell cycle pathways. Cell Cycle 2008, 7(12):1745-1762

35. Masramon L, Arribas R, Tortola S, Perucho M, Peinado MA: Moderate amplifications of the c-myc gene correlate with molecular and clinicopathological parameters in colorectal cancer. Br J Cancer 1998, 77(12):2349-2356.

36. Lagerholm S, Dutta S, Nair P: Non-invasive detection of c-myc p64, c-myc p67 and c-erbb-2 in colorectal cancer. Scand J Gastroenterol 2005, 40(11):1343-1350.

37. Matsushita K, Takenouchi T, Shimada H, Tomonaga T, Hayashi H, Shioya A, Komatsu A, Matsubara H, Ochiai T: Strong HLA-DR antigen expression on cancer cells relates to better prognosis of colorectal cancer patients: Possible involvement of c-myc suppression by interferon-gamma in situ. Cancer Sci 2006, 97(1):57-63.

38. Nasi S, Ciarapica R, Jucker R, Rosati J, Soucek L: Making decisions through Myc. FEBS Lett 2001, 490(3):153-162.

39. Karpinski P, Sasiadek MM, Blin N: Aberrant epigenetic patterns in the etiology of gastrointestinal cancers. J Appl Genet 2008, 49(1):1-10.

40. Konishi K, Issa JP: Targeting aberrant chromatin structure in colorectal carcinomas. Cancer J 2007, 13(1):49-55.

41. Kondo Y, Issa JP: Epigenetic changes in colorectal cancer. Cancer Metastasis Rev 2004, 23(1-2):29-39.

42. Atadja P: Development of the pan-DAC inhibitor panobinostat (LBH589): successes and challenges. Cancer Lett 2009, 280(2):233-241.

\section{Pre-publication history}

The pre-publication history for this paper can be accessed here: http://www.biomedcentral.com/1471-2407/10/610/prepub

doi:10.1186/1471-2407-10-610

Cite this article as: Gao et al:: Oridonin induces apoptosis and senescence in colorectal cancer cells by increasing histone hyperacetylation and regulation of p16, p21, p27 and c-myc. BMC Cancer 2010 10:610.

\section{Submit your next manuscript to BioMed Central and take full advantage of:}

- Convenient online submission

- Thorough peer review

- No space constraints or color figure charges

- Immediate publication on acceptance

- Inclusion in PubMed, CAS, Scopus and Google Scholar

- Research which is freely available for redistribution

Submit your manuscript at www.biomedcentral.com/submit
C Biomed Central 